\title{
La educación sentimental. O de la difícil cohabitación de razones y emociones
}

\author{
FERNANDO BRONCANO \\ Universidad Carlos III de Madrid
}

«The whole nature of man... may all be comprehended in these four: strenght of body, experience, reason, and passion.»

Hobbes, Elements of Law

RESUMEN. La tradición filosófica ha tenido siempre dificultades para considerar las emociones desde el punto de la racionalidad. Sin embargo, hay contextos en los que la evaluación racional debe tomar en cuenta necesariamente un componente de sensibilidad emocional. Estos contextos son los grandes proyectos vitales, que pueden ocupar un fragmento apreciable de la vida, cuando no toda ella. En ellos podemos decir con cierta propiedad que un fracaso afectivo absoluto es un fracaso racional. En este trabajo proponemos un modo de análisis de las emociones como tipos especiales de representaciones (representaciones directivo-descriptivas) que nos permitirá enfocar las relaciones entre emociones y racionalidad de una forma más matizada.
Abstract. Traditionally, philosophy has confronted difficulties to cope with emotions from the view of rationality. Notwithstanding, there are contexts that claim an emotional sense in the rational evaluation. This sort of contexts are for example the life projects extending over an apreciable fragment of a life-time. We can say of them that an afective failure is also a failure of rationality. In this paper we propose an account of emotions as a special sort or representations, i.e., as descriptive-directive representations. That analysis will allow us to see more carefully the relationships between reasons and emotions.

\section{Una noción autosocavante de racionalidad ${ }^{1}$}

Al comienzo del invierno, Frédéric y Deslauriers charlan junto al fuego acerca de en lo que ha devenido su vida. Los dos amigos han compartido experiencias

\footnotetext{
${ }^{1}$ Este trabajo se ha beneficiado de la ayuda de los proyectos SA 07/99 de la Junta de Castilla y León y PB 98-0495-C08-03 de la DGCYT. Las discusiones con Jesús Vega, Carlos Thiebaut y David Konstan han sido esenciales para su redacción. Carlos Moya me ha hecho correctas sugerencias que no estoy seguro de haber satisfecho. He desarrollado algunas ideas complementarias y previas a las que aquí se exponen en F. Broncano, «Las emociones como territorios intermedios en la mente», en Pascual Martínez Freire (ed.), Filosofía contemporánea de la mente (en prensa).
} 
en una itinerante sucesión de encuentros y desencuentros que comenzó en su primera juventud y llega hasta ahora, retirados en provincias de las pasiones parisinas:

«Y resumieron sus vidas.

Ambos la habían malogrado, tanto el que había soñado con el amor como el que había soñado con el poder. ¿Cuáles podían ser las razones?

-Quizá haya sido por falta de una línea recta —-dijo Frédéric.

-En cuanto a ti, es posible. Yo, al contrario, he pecado por exceso de rectitud, sin tener en cuenta que hay mil cosas secundarias más fuertes que todo. Yo tenía demasiada lógica y tú demasiado sentimiento.

Acusaron luego al azar, a las circunstancias, a la época en que habían nacido.

Frédéric añadió:

- No era eso a lo que aspirábamos en otros tiempos, en Sens, cuando tú querías hacer una historia crítica de la Filosofía, y yo una gran novela medieval sobre Nogent, cuyo tema había encontrado yo en Froissart: de cómo el caballero Brokars de Fénestranges y el obispo de Troyes acometieron al caballero Eustache d'Ambrécicourt. ¿Te acuerdas?

Y exhumando su juventud en cada frase, se decían:

- ¿Te acuerdas?» (Gustave Flaubert, La educación sentimental, traducción de Miguel Salabert, Madrid, Alianza, 1981, p. 576).

La educación sentimental de Flaubert y La lucha de clases en Francia y El dieciocho brumario de Luis Bonaparte de Marx son libros que ganan mucho si son leídos el primero de ellos contra el transfondo de los otros dos (y viceversa). Las dos historias son historias de fracasos, personal el primero y colectivo el segundo. La educación sentimental es una historia de iniciación, de transición al estado de adulto de un joven enamorado de una mujer casada con un empresario. También es una historia generacional en la que los personajes, que desarrollan su existencia en el París revolucionario, adquieren un carácter simbólico. Y aquí es donde La lucha de clases en Francia y El dieciocho brumario nos sirven de contexto. El final de la monarquía, la breve revolución republicana y la restauración bonapartista son también procesos de experiencia y aprendizaje colectivos. Para Marx, las revoluciones francesas fueron sus primeras y más cercanas experiencias revolucionarias, su propio aprendizaje de lo que podría ser una revolución; y, como Flaubert, Marx comprueba la magnitud de un fracaso, aunque salve la experiencia como un aprendizaje de desconfianza colectiva. Se propone demostrarnos que la derrota del movimiento francés le sirvió en realidad como experiencia fundacional: los levantamientos espontáneos y pasionales de 1848-1850 volvieron acaso más tristes pero sin duda más sabios a los militantes obreros parisinos. El fracaso de la revolución que el proletariado había emprendido conjuntamente con la burguesía dio paso al nacimiento de un movimiento autónomo y maduro, capacitado para emprender más ambiciosas tareas que veinte años más tarde llevaron a la Comuna. Mas el hecho es que se narra la historia de una horrible derrota seguida de una atroz venganza. 
La tesis que quiere demostrarnos Marx no oculta un cierto aire de paradoja. No es casual que El dieciocho brumario se inicie con uno de los más desesperados juicios que se hayan hecho en teoría social:

«Los hombres hacen su propia historia, pero no la hacen a su libre arbitrio, bajo circunstancias elegidas por ellos mismos, sino bajo aquellas circunstancias con que se encuentran directamente que existen y transmite el pasado. La tradición de las generaciones muertas oprime como una pesadilla el cerebro de los vivos. Y cuando éstos se disponen precisamente a revolucionarse y a revolucionar las cosas, a crear algo nunca visto, $[\ldots]$ conjuran temerosos en su auxilio los espíritus del pasado, toman prestados sus nombres, sus consignas de guerra [...] Es como el principiante que ha aprendido un idioma nuevo: lo traduce siempre a su idioma nativo, pero sólo se asimila el espíritu del nuevo idioma y sólo es capaz de producir libremente en él cuando se mueve dentro de él y olvida en él su lengua natal» (Marx, El dieciocho brumario de Luis Bonaparte).

La hermosa revolución del 48 celebrada por todo el pueblo de París se convierte en una revuelta de barricadas y en un posterior golpe de Estado. Si el futuro de un movimiento colectivo es alejarse cuanto antes del entusiasmo y prepararse para la experiencia de la traición y el desencanto, los dilemas de racionalidad que nos presentan la teoría de juegos y la lógica de la acción colectiva desentrañan una más constitutiva incapacidad de nuestras capacidades de socialidad.

En La educación sentimental, Flaubert tiene un propósito no menos ambicioso que Marx. Refiriéndose al propósito de la obra que está escribiendo, escribe a una amiga:

«Quiero hacer la historia moral de los hombres de mi generación; «sentimental» sería un término más certero. Es un libro de amor, de pasión, pero de pasión tal como puede existir ahora, es decir, inactiva» (Carta a Mme. La Royer de Chantepie, 8 de octubre de 1864$)^{2}$.

La historia sentimental es vivida como una historia de desencanto que abre el camino a una experiencia mucho más profunda, sutil y matizada. En una gloriosa escena de despedida, el protagonista de la historia, Frédéric Moreau, renuncia a tomar en sus brazos al objeto por tantos años de sus sueños y deseos, a su amada Sra. Arnoux, ahora viuda y libre, que se acerca a su casa con el confesado fin de ceder a sus requerimientos. Pero inexplicablemente ambos se descubren incapaces de realizar su pasión tal como ha predicho su autor Flaubert. Su pasión se ha transmutado en nostalgia y tras largos años de esperar este instante se hallan impotentes para expresar sus deseos. Hay en esta irrealizabilidad una patología más grave que la akrasía.

\footnotetext{
${ }^{2}$ Citada en el prólogo de Salabert a su traducción de la obra de Flaubert. Este prólogo ha inspirado en buena parte mi elección de La educación sentimental como paradigma del tema que trata este trabajo. El hecho de que una generación aprenda o se equivoque como tal es precisamente el motivo de las dos obras de Marx y Flaubert.
} 
Su fracaso tiene que ver con la formación de la motivación cuando esta involucra largos planes que afectan a una vida entera. $\mathrm{Y}$ en tal estado su enfermedad sentimental no es, no puede ser, ajena a una falta de racionalidad.

Flaubert no juzga a Frédéric, se limita a mostrarnos su trayectoria por los convulsos años personales y colectivos que le han tocado vivir. Es a nosotros lectores a quienes compete extraer conclusiones sobre este fracaso histórico que Flaubert conjetura como desactivación de la pasión y como incapacidad de expresión emocional que afecta a toda la generación a la que pertenece Frédéric. A nosotros filósofos se nos exige pensar las condiciones bajo las que una trayectoria que configura la personalidad, el carácter, e incluso toda una experiencia colectiva (la del proletariado insurgente) pueden ser juzgados a la luz de las perspectivas normativas de la racionalidad y la moralidad. ¿Cabe hablar de racionalidad en estos enormes marcos narrativos?, ¿cómo se relacionan las experiencias emocionales y las decisiones prácticas?, ¿cómo afecta esta relación a la racionalidad y la moralidad?, ¿cómo debemos pensar las emociones sabiendo que nos obligan normas de racionalidad y moralidad?

La racionalidad en el dominio social tiene que ver con el juego de normas, intereses y pasiones en un contexto sometido a graves dilemas de acción colectiva como los que nos señalan las ciencias sociales. En este dominio se crean hábitos, instituciones, compromisos, normas y contratos que configuran la historia colectiva. Si cabe hablar de un modo no trivial de racionalidad y moralidad debería ser por referencia a unidades de juicio suficientemente largas como para despejar las dudas sobre el desesperado escepticismo que Marx ha suscitado. Y lo mismo cabe afirmar de la evolución personal. Si no es posible la formación de un carácter, la libre decisión de adquirir hábitos virtuosos, la teoría de la racionalidad y la moralidad quedarían reducidas al oscuro sometimiento a un destino que nos ha sido dado, a la aplicación de normas a decisiones atómicas, pero no a la capacidad de autodeterminar las constricciones bajo las que esas normas adquieren contenido.

La racionalidad colectiva y la racionalidad a medio plazo, las racionalidades de trayectorias vitales y colectivas o generacionales, comparten similares dilemas y antinomias, es cierto; pero si no nos es dado hablar de racionalidad en estos contextos, es que nuestra teoría de la racionalidad es más bien menguada. Lakatos sostuvo, creo que con razón, que no hay racionalidad instantánea. No es necesario bajar al infierno hegeliano para sostener que la racionalidad se predica de proyectos, de episodios, de aventuras, de instituciones. La racionalidad ideal del teórico que nos lleva a estipular las condiciones en las que aparcar en doble fila es preferible a dar una vuelta a la manzana está bien como análisis propedéutico que nos ayuda a pensar las constricciones impuestas por la propia representación de la situación de decisión, dada nuestra constitución psicológica, tal como la estipula la teoría natural de creencias-deseos.

La racionalidad es uno de nuestros conceptos normativos, una condición imprescindible que constriñe a otras instancias como la moralidad o la dinámica 
epistémica de la creencia. Al igual que la moralidad, lo racional no se deja reducir a la descripción de cómo somos, pero no puede alejarse tampoco demasiado de ese territorio. Owen Flanagan ha denominado a este requisito Principio de Realismo Psicológico: la fuerza normativa de los principios de racionalidad y moralidad debe ser realizable en dotaciones psicológicas como la nuestra ${ }^{3}$. El economista Ken Binmore, refiriéndose al principio de contrato social, y teniendo en su ojo de mira a las teorías neokantianas, ha subrayado más formalmente este requisito como un principio de estabilidad ${ }^{4}$ : un conjunto de normas que no se autorrefuerce por la lógica de su realización social está condenado a convertirse en letra muerta. Y de nuevo Lakatos, más castizo, propone que las éticas utópicas (y las teorías de la racionalidad con ellas) se contrasten por el grado en que conducen a crear morales hipócritas.

$\mathrm{Si}$ en cualquier escala de la acción las emociones cumplen una función innegable en la constitución psicológica de la motivación y de la interpretación de las acciones ajenas, no hay más remedio que discutir cuidadosamente las extrañas relaciones de las emociones con la racionalidad. Pues, insistimos, un fracaso colectivo o personal de la dimensión que nos presentan Marx y Flaubert debe ser entendido como un fracaso de la racionalidad. Si un fracaso emocional tiene que ver algo con la racionalidad es porque nos cabe autoatribuirnos alguna responsabilidad respecto a las emociones y hablar de emociones irracionales ${ }^{5} \mathrm{y}$, consecuentemente, porque nos embarcamos en el compromiso de una posible educación sentimental. Del mismo modo que una ética de la creencia nos demanda la adquisición de la mayor información posible y de los mejores hábitos y destrezas cognitivas de los que seamos capaces, la virtud de la racionalidad conlleva la formación de adecuadas disposiciones emocionales, la constitución de habilidades de discriminación y una respuesta emocional aceptable ante situaciones objetivas que socialmente la exijan.

Hay varias dificultades con las relaciones entre la racionalidad y las emociones, pero la más inquietante no proviene, como se ha pensado tantas veces a lo largo de la historia, del hecho que las emociones sean eventos perturbadores de la racionalidad, sino de la curiosa situación que presenta el que las emociones sean funcionalmente activas en la memoria y quizás en las decisiones prácticas, dado el modo en el que está constituido nuestro sistema cognitivo, mientras que el sistema racional se piense ligado sólo contingentemente a las emociones ${ }^{6}$.

${ }^{3}$ Owen Flanagan, Varieties of Moral Personality. Ethics and Psychological Realism, Cambridge, MA, Harvard University Press, 1991, p. 32.

${ }^{4}$ K. Binmore, Playing Fair. Game Theory and the Social Contract, vol. 1, Cambridge, MA, MIT Press. Uno de los temas de este texto, dedicado a «dekantianizar a Rawls», es que la capacidad de empatía sentimental es una precondición de la racionalidad y la moralidad.

5 R. de Sousa, The rationality of emotions, 1987; P. S. Greenspan, Emotions and reasons, Londres, Routledge, 1988; J. Oakley, Morality and the emotions, Londres, Routledge, 1992.

${ }^{6}$ Los datos de neurofisiólogos como LeDoux y Damasio son bastante concluyentes respecto a la acción del sistema límbico sobre el córtex prefrontal. Los daños en este sistema tienen efectos sobre la memoria y la capacidad de aprendizaje, sobre la capacidad de sostener compromisos 
Si portan alguna forma de contenido se nos plantea el siguiente dilema: o bien actuamos por el contenido de las emociones o bien actuamos por el contenido de las razones. Si los dos contenidos están desconectados, entonces estamos abocados al proverbio pascaliano de que hay razones del corazón que la razón ignora, lo que no puede ser visto sino como un fracaso racional o como un defecto evolutivo de nuestra constitución; y si los dos contenidos están conectados, al fin y al cabo son las razones las que mandan y deben mandar, luego el contenido emotivo no sería más que un subproducto, un apéndice que es prescindible, cuando no dañino.

Lo primero que debemos notar es que las razones para la acción tienen que ser suficientes (condición de agencia) y adecuadas (condición de racionalidad). El requisito de suficiencia nos conduce a una cierta forma de entender la fuerza motivacional de la acción: las razones, entendidas como complejos cognitivos de creencias e intenciones deben ser causalmente suficientes para producir la acción. En otro caso, la acción quedará reducida al mero estadio de «conducta». El requisito de adecuación es un requisito normativo: las razones deben ser razones adecuadas respecto a ciertas condiciones normativas o principios de racionalidad. Hasta aquí nos hallamos en el terreno de la teoría de la acción intencional «mainstream», sin entrar en cualificaciones más finas acerca de la necesidad o no de intenciones. Por otra parte, debemos atender con cuidado a las nuevas teorías funcionalistas de las emociones. Tales concepciones han sido postuladas por un amplio espectro de autores que va desde neurofisiólogos (Antonio Damasio, Josep LeDoux) y psicólogos (Keith Oatley) hasta filósofos, entre los que cabe señalar a David Casacuberta y Jose Antonio Marina ${ }^{7}$. Sea cual sea la función concreta que realice el sistema emotivo,

y motivaciones a largo plazo e incluso sobre la propia configuración de la personalidad. Parece incluso que el Síndrome de Personalidad Múltiple lleva asociada la activación de regiones distintas de la amígdala. Según LeDoux el sistema límbico actúa en primer lugar como un sistema muy rápido de detección y acción, más rápido que el sistema perceptivo que implica reconocimiento conceptual. En este funcionamiento actúa de modo paralelo (aunque no redundante) con el sistema perceptivo cognitivo. Pero también actúa a través de sus proyecciones a las regiones superiores como filtro de relevancia de la información, asociado al aprendizaje. Puede que muchos de estos datos se modifiquen en el futuro, pero sería un error reflexionar sobre la naturaleza de la racionalidad como si no existieran. (Véanse, J. LeDoux, El cerebro emocional, Barcelona, Planeta, 1999; A. R. Damasio, El error de Descartes. La emoción, la razón y el cerebro humano, Barcelona, Crítica, 1999; R. Adler, «Crowded Minds», New Scientist, 2217, 18 de diciembre de 1999; G. E. Tsai et al., «Functional magnetic resonance imaging of personality switches in a woman with Dissociative Identity Disorder», Harvard Review of Psychiatry, 7, p. 19.)

7 Véanse, como muestras del reciente funcionalismo, LeDoux, op. cit., y Damasio, op. cit.; $\mathrm{K}$. Oatley, Best laid schemes. The psychology of emotions, Cambridge, Cambridge University Press, 1992, así como los trabajos recogidos en la exhaustiva antología de P. Ekman y R. J. Davidson (eds.), The nature of emotion. Fundamental questions, Oxford, Oxford University Press, 1994; R. S. Lazarus y B. N. Lazarus, Passion and reason. Making sense of ou emotions, Oxford, Oxford University Press, 1994; Aaron Ben-Ze'ev, The subtlety of emotions, Cambridge, MA., MIT Press, 2000; J. A. Marina, El laberinto sentimental, Barcelona, Anagrama, 1996; D. Casacuberta, ¿Qué es una emoción?, Barcelona, Crítica, 2000. Sobre la relevancia en general para la concepción funcionalista de la 
el punto central de la concepción funcionalista es que las emociones no son meros procesos «viscerales», sino que tienen componentes cognitivos y han evolucionado por sus componentes cognitivos.

Tenemos, pues, de un lado la necesidad de que exista un «contenido» productor de la acción y del otro la razonable convicción de que el sistema emotivo, aunque parcialmente autónomo, promueve procesos emocionales con su propio contenido cognitivo y práctico. Formulando de otro modo nuestro dilema, si el contenido mental que causa las acciones resulta de procesos de inferencia que son ajenos a las emociones que despierten o estén implicadas en el proceso de inferencia, entonces, si fuera el caso que, pese a todo, hubiese cierta «racionalidad» en el comportamiento emocional, cabría pensar que la racionalidad estaría entonces ligada a las emociones solamente por un lazo contingente, quizá por el simple hecho casual de que hemos evolucionado con esta constitución mental tan chapucera, de manera que no sería posible derivar conclusión normativa alguna. $\mathrm{Y}$ en un cierto sentido cabe pensar en seres extraños que hayan evolucionado de forma diferente a la nuestra y que, sin embargo, interactúen, si tal fuera el caso, de manera «normal» con nosotros. Es la posibilidad que nos plantean seres como el Doctor Spock de Star-Treek y quizá es una posibilidad muy real atendiendo a la configuración psicológica de algunas formas de psicopatía. Si el sistema emocional deviniera en una mera excrecencia, en un subproducto evolucionario, no sería entonces más que una constricción con la que habría que contar en la teoría de la racionalidad, lo mismo que ocurre con nuestras limitaciones computacionales, pero no como un elemento constitutivamente activo y funcional en el sistema de decisiones racionales.

Y no obstante, hay razones para resistirnos a esta inveterada conclusión. Los casos que nos presentan Marx y Flaubert tienen que ser considerados necesariamente como graves fracasos personales y colectivos y, en consecuencia, como catástrofes de la racionalidad. De ahí que una teoría de la racionalidad que promueva su autosuficiencia respecto a la vida emocional haya que sospecharse como autosocavante. El adjetivo de autosocavante implica que en ocasiones es más racional no ser racional que serlo ${ }^{8}$. Una teoría de la racionalidad que permita estas consecuencias debe ser revisada sin dilación.

mente, P. Martínez Freire, «El desafío de las emociones a las ciencias cognitivas», Themata 25, 2000, 55-66.

El, por muchas razones, admirable y clásico texto de D. Parfit, Reasons and persons, Oxford, Oxford University Press, 1984, distingue entre teorías de la racionalidad que son directamente autorrefutadoras y las que lo son indirectamente. Las directamente autorrefutadoras son las que implican que es más racional no ser racional de acuerdo a la teoría propuesta, las que lo son indirectamente son aquellas que proponen objetivos cuya consecución es a la larga peor que el no conseguirlos. El argumento que presentamos aquí no distingue las teorías de la racionalidad por sus objetivos teóricos (T-objetivos, según Parfit: autointerés, felicidad, etc.), sino por las unidades que evalúan. La tesis es que las teorías de la racionalidad instantánea, por oposición a las teorías históricas o narrativas, son indirectamente autosocavantes. A modo de ejemplo, aun a riesgo 


\section{La heterogeneidad funcional y el contenido cognitivo de las emociones}

Si hay algún camino para resolver o al menos soslayar los dilemas que presentamos tendrá que encontrarse revisando la fuente de donde nacen, que no es otra que la forma de pensar el contenido mental sobre la que construimos más tarde la idea de racionalidad. El primer paso es reflexionar sobre la idea funcionalista de que las emociones portan contenido cognitivo. Esta revisión se asienta sobre el supuesto de que el sistema cognitivo es un sistema funcional complejo ${ }^{9}$ y que asimismo lo es el sistema emotivo, con el que tiene relaciones de interacción. Entre los aspectos de la complejidad emotiva está la variedad de niveles en la que se realiza: bioquímicos, neuroanatómicos, neurofisiológicos, fisiológicos, conductuales y, por último y relevante a nuestro argumento, $\operatorname{cog}$ nitivos. Al igual que ocurrió con el sistema perceptivo, las presiones evolutivas que configuraron el sistema emotivo fueron variadas y actuaron de formas variadas sobre estos heterogéneos aspectos. Pero, de toda la historia filogenética de las emociones, lo que importa subrayar es que contienen cierto contenido cognitivo, y que este contenido es el que causa una parte sustancial del comportamiento emocional y de otras consecuencias que tienen las experiencias emocionales sobre los procesos mentales. El punto relevante es que si las emociones se limitaran a ser meros componentes «viscerales» no tendrían capacidades de acción a causa de la información que contienen.

Muchas discusiones acerca del contenido cognitivo de las emociones nacen de la equivalencia entre lo cognitivo y la formulación consciente, conceptual y regularista de la información. Así, los más proclives a considerar cognitivamente las emociones tienden a asimilarlas a actitudes proposicionales e incluso a juicios evaluativos de información. En el lado contrario, quienes quieren subrayar el aspecto «visceral» de las emociones tienden a subrayar los aspectos automáticos de los procesos emocionales al margen del reconocimiento consciente de la emoción actuante ${ }^{10}$. Mas las dos posiciones extremas comparten

de ser injusto con él, el davidsoniano Jon Elster, que ha argumentado en numerosos libros que lo que él llama mecanismos, entre los que están las emociones, son «mecanismos» porque entran dentro del orden causal, por consiguiente, irracional, especialmente en su Ulysses and the Sirens, Cambridge, Cambridge University Press, 1984, en Jon Elster, Ulysses unbound, Cambridge, Cambridge University Press, 2000, tiene que reconocer que los anteriormente mecanismos, ahora «autoconstricciones», son los ejercicios de racionalidad en plazos largos como los planes de vida.

' Como sistema, contiene subórganos, procesos y conductas con interrelaciones entre sí y con otros sistemas de la constitución psicológica humana. El que sea funcional entraña que el sistema ha sido seleccionado porque realiza determinadas conductas que fueron adaptativas en el momento de su selección y que lo han seguido siendo a lo largo de su preservación a lo largo de la sucesión de generaciones. El que sea complejo es postulado a causa de la heterogeneidad de propiedades y características en las que se muestra la acción del sistema emotivo.

${ }^{10}$ S. Schachter y J. Singer, «Cognitive, social, and physiological determinants of emotional state», Psychological Review, 69, 1962, pp. 379-399, llevaron a cabo unos experimentos ya clásicos en los que una activación fisiológica inducida artificialmente podía producir emociones diferentes 
una misma concepción cognitiva de la mente que separa lo cognitivo de lo emotivo, es decir, que niega la posibilidad de aspectos cognitivos no integrables en el modelo lingüístico de procedimientos y reglas computacionales. Pero esta misma condición la comparten otras varias entidades psicológicas menos sospechosas para la tradición filosófica. Por ejemplo, los esquemas sensorio-motores y las habilidades.

El sistema emotivo es un sistema de control ${ }^{11}$ entre otros muchos que conforman la mente. Pero un sistema de control con sus propias actuaciones incorporadas. Las funciones que cumple se pueden resumir en estas tres: a) detección de objetivos relevantes, $b$ ) preparación corporal para llevar a cabo ciertos planes de conducta preprogramados como respuesta a los objetivos señalados, $c$ ) sostenimiento de los objetivos a lo largo de la trayectoria vital componiendo un sistema de motivación. En la primera de las funciones sirve como sistema de alerta temprana que informa de algo relevante para los planes en los que está embarcada la persona a corto o largo plazo: detecta información relevante en el medio externo, incluida la información a la que pudiera accederse sobre los estados mentales de otras personas, pero también información relevante en el medio externo, proviniente de la memoria, de la imaginación o del razonamiento. En la segunda de la funciones, el sistema emotivo funciona como un sistema ejecutor que induce cambios fisiológicos en el cuerpo necesarios para la acción. En la tercera de las funciones, el sistema emotivo se muestra como un sistema que interactúa con el cognitivo a través de la conformación de la memoria. Su acción sobre la memoria más importante es como marcador motivacional ${ }^{12}$.

Dentro de una concepción de la mente como sistema simbólico hecho a imagen y semejanza del lenguaje, dotado de un sistema central de control, la conciencia, es decir, dentro de una concepción de la mente que se ha venido en calificar de «cartesiana», esta heterogeneidad de las funciones emocionales colabora en la justificación de la actitud de sospecha que ha dominado tradicionalmente. Pero en una concepción de la mente menos centralizada, más cercana a un sistema dinámico que a un sistema de representaciones lingüísticas

cuando se complementaban con información cognitiva externa. Las teorías viscerales parecían entonces en retroceso, pero R. Zajonc, «Feeling and thinking: preferences need no inferences», American Psychologist, 35, 1980, pp. 151-175, mostró en otros experimentos que las emociones podían conformar las decisiones antes de que el sistema cognitivo hubiera tenido tiempo de actuar. J. Elster, Strong feelings. Emotion, adiction and human behavior, Cambridge, MA, MIT Press, 2000, subraya los componentes viscerales.

${ }^{11}$ La noción de la mente como un complejo dinámico de sistemas de control se propone en R. F. Port y T. van Gelder (eds.), Mind as motion. Explorations in the dynamics of cognition, Cambridge, MIT Press, 1995.

${ }^{12}$ Un estado motivacional puede ser descrito cognitivamente por la función de utilidad que se asocia a una representación de un estado, que puede ser más o menos deseable o aborrecible. El sistema emotivo cambia las funciones de utilidad y es el sistema involucrado en la marca moral, estética y, en general, en los compromisos en los que se embarca el sistema cognitivo (véase Elster, op. cit., 2000). 
secuenciales, más externista e interaccionista con el medio y más «encarnada», en la que los sistemas de procesamiento hayan sido configurados por las capacidades, esquemas y rutinas de acción ${ }^{13}$, la heterogeneidad funcional de los procesos emocionales tiene una acogida natural. En esta concepción de la mente es posible dar cuenta de cómo el contenido portado y producido por los sistemas emotivos puede realizar esta heterogeneidad funcional. En esta concepción de lo mental ni todo lo cognitivo es consciente ni lo consciente es capaz de representar los modos reales por los que se está procesando la información, e incluso la información que se está procesando en el cerebro. Muchos filósofos de la mente llegaron a aceptar a regañadientes este hecho referido a procesos como las gramáticas subyacentes, sin ser capaces de extenderlo al conjunto de nuestros sistemas cognitivos. Pero hay muchas razones de orden empírico y conceptual para pensar que la mente tiene mucho más de una asociación contingentemente estable de muchos órganos y sistemas de control con capacidades representacionales propias que, por otra parte, se solapan parcialmente y se intercomunican y, a veces, se constriñen mutuamente. El sistema emotivo y el conceptual es un caso, aunque hay otros tales como el sistema conceptual y el perceptual, el sensorio motor y el conceptual, etc.

Se puede dar cuenta de la complejidad funcional de las emociones si aceptamos que el sistema emotivo es capaz de procesar un tipo peculiar de representaciones no conceptuales, pero que pueden pasar a formar parte del contenido conceptual si interactúan con las representaciones conceptuales. Se trata de representaciones que Ruth G. Millikan ${ }^{14}$ ha caracterizado como representaciones descriptivo-directivas (RDD, en adelante). Son representaciones que detectan información y activan órdenes de acción. Las condiciones de satisfacción de una representación representacional van de la mente al mundo, las de una representación directiva van del mundo a la mente. En el feliz ejemplo de Searle, una lista de compra puede ser directiva para un comprador: debe adaptar el mundo (el carro de la compra) a la lista (objeto representacional), mientras que para el detective que toma nota de la conducta del comprador, la misma lista de compra tiene otras condiciones de satisfacción, va del mundo (el carro de la compra) a la mente, la lista de la compra. Las representaciones directivas y las descriptivas puras tienen, pues, una semántica muy diferente, pero hay también representaciones mixtas, las representaciones más primitivas en el orden filogenético, representaciones que comparten ambas condiciones de satisfacción. Millikan pone el ejemplo de la llamada de la gallina a sus polluelos, una llamada traducible en términos disneylandianos como «iAquí hay comida!, ivenid, comed!».

\footnotetext{
${ }^{13}$ Una buena introducción a esta noción «encarnada» y «extendida» de la mente es A. Clark, Being there. Putting brain, body and world together again, Cambridge, MA, MIT Press, 1997.

${ }^{14}$ R. G. Millikan, «Pushmi-pullyu Representations», en L. May, M. Friedman y A. Clark (eds.), Minds and Morals. Essays on Ethics and Cognitive Science, Cambridge, MIT Press, 1996.
} 
«Su función es mediar la producción de una cierta suerte de conducta que varía como función directa de una cierta variación del medio, traduciendo así directamente la forma del medio en la forma de una cierta clase de acción que se conforma a aquél» (Millikan, 1996, p. 151).

Millikan nos aclara que estas representaciones no son meras conjunciones de una descripción con una representación directiva: son representaciones aún más primitivas que la evolución reutiliza e incorpora a estadios de organización mental más complejos que los de la mente animal. En particular, Millikan piensa que algunas RDD están presentes en las representaciones de roles sociales y normas (por ejemplo, en las representaciones que nos hacen conducir por la derecha), en algunos performativos (votar con la mano levantada). Lo importante es que estas representaciones activan rutinas relativamente enclaustradas respecto a la información superior, más representables y transformables si las circunstancias lo exigen, como ocurre cuando uno comprueba que no es el momento de votar o que la situación exige cambiar de carril.

Tenemos así unos buenos candidatos para conseguir que el contenido emotivo alcance el grado de contenido representacional sin navegar por los peligrosos rumbos del proposicionalismo. Los contenidos emocionales, por conscientes que sean, no son actitudes proposicionales como tampoco lo son los esquemas sensorio-motores y, sin embargo, no carecen por ello de contenido representacional.

Los postulados del funcionalismo respecto a las emociones al que nos conduce la idea de los procesos emocionales como RDD son:

1. Entrañan un tipo primitivo de representaciones que tienen su propia espontaneidad

2. No están activadas necesariamente por el conocimiento, sino por múltiples fuentes.

3. Tienen una dinámica propia.

4. Su contenido no es conceptual, sino protoconceptual (RDD).

5. Es un contenido que, sin embargo, constriñe a los conceptos futuros.

6. Es modificado por los conceptos: ayudan a discriminar más y así cumplen de modo más fino sus funciones.

Los tres primeros puntos dan cuenta de la prioridad y autonomía del sistema emotivo: no tendría sentido un planteamiento especial respecto a las emociones si no tuviesen también un estatuto peculiar en nuestra arquitectura mental. Si fuesen objetos cuasi-proposicionales no habría que plantearse tal estatuto sui-generis, y si no son más cognitivos que los movimientos reflejos tampoco ha lugar este estatuto. Los puntos más controvertibles de esta posición son los que nos llevan a postular la profunda relación del contenido conceptual con un estrato de contenidos representacionales aún no conceptuales. Dentro de una concepción ortodoxa de los conceptos tal posibilidad está prohibida. 
Los conceptos solamente pueden ser entidades lingüísticas, puesto que entran en redes inferenciales lingüísticas ${ }^{15}$. En la concepción en la que encaja nuestra noción de emociones, los conceptos son habilidades cuya maestría solamente es en parte lingüística, además necesitan un transfondo de contenidos no conceptuales sin los cuales las habilidades recognoscitivas no pueden ser ejercidas. Y entre este transfondo de contenidos no conceptuales, las RDD constituyen una parte de la materia de la que están hechos los conceptos ${ }^{16}$.

Al extender la noción de estado mental hasta un territorio que debería llenar la cesura entre las actitudes proposicionales «full-fledged» y los mecanismos causales rampantes (tropismos, reflejos, etc.) no ha sido nuestra intención, anticipándonos a alguna malévola sospecha, rebajar las condiciones y compromisos que introduce en lenguaje en el contenido mental con el oculto deseo de rebajar al tiempo los niveles de calidad de las decisiones racionales. No, se trata más bien de lo contrario, de penetrar en la naturaleza de las normas racionales sabiendo que las inferencias se establecen a través de sutiles lazos que conectan relaciones de relevancia entre contenidos aparentemente lejanos y ajenos. Y, si en tales relaciones inferenciales obran principios lógicos, es decir, sintácticos y semánticos, también lo hacen regularidades que el sujeto almacena en diversos formatos de prototipos, conclusiones "por defecto» y otros modos no monotónicos de extraer información de la información que ya está contenida en la mente del sujeto. Aquí, los estratos preconceptuales (si ocurriese que estuviesen conectados mediante vías informacionales de ida y vuelta con los estratos representacionales superiores con formato lingüístico y tenemos buenas razones para pensar que tal es el caso) conformarían la propia sustancia de la que están hechas las inferencias (extraer información de la información) y, por consiguiente, estarían en el campo y dominio de la racionalidad. Pero la racionalidad pudiera ser una capacidad normativa sin normas rígidas: la habilidad de elegir en cada contexto aquellas inferencias y decisiones que sean adecuadas. Por ello quizá sea prudente no disponerse demasiado rápido a eliminar o enaltecer la contribución de las emociones a la racionalidad.

${ }^{15} \mathrm{Su}$ función, en la concepción fregeano-cartesiana, es producir proposiciones con un valor de verdad definido. Esta posición exige un salto entre los contenidos lingüísticos y los no lingüísticos que no admite representaciones intermedias. Tales entidades serían como mecanismos circuitados en un robot: información que no puede entrar a formar parte de las inferencias y por ello de los razonamientos y, por consiguiente, no puede ser susceptible de evaluación racional.

${ }^{16}$ Como ocurre con otros muchos contenidos protoconceptuales, también cabe una metarrepresentación de la emociones y, por consiguiente, una «evocación» lingüística de las emociones. Si las emociones no pudieran ser evocadas tampoco podrían ser convocadas en la literatura y en la argumentación retórica o en el uso de la metáfora. Difícilmente podrían servir de fuentes de información estas obras si no hubiese forma de evocar el contenido emotivo. El modo de presentación de las emociones evocadas no tiene por qué ser el mismo de las emociones experimentadas. Pero, si las emociones forman una clase natural, son también medios para reconocerlas. 


\section{La racionalidad/moralidad de las emociones: pesimismos y optimismos}

Ronald de Sousa ${ }^{17}$ nos recuerda que habitualmente empleamos expresiones como «es irracional este miedo que tienes a las arañas» o, por el contrario, «es natural que sientas miedo a la carretera», expresiones que entrañan que en algún sentido estamos abiertos a una cierta evaluación de nuestras propias emociones. Lo mismo podríamos afirmar respecto a la posible evaluación moral de las emociones. Si hay sentimientos morales es porque podemos juzgar las emociones. ¿Es cierta esta posiblidad?

Si podemos juzgar o al menos evaluar estos procesos mentales del mismo modo que deliberamos sobre creencias o sobre fines y valores, parece implicarse una responsabilidad acerca de las ocurrencias de emociones, del mismo modo que tenemos una no enajenable responsabilidad moral y racional acerca de nuestras creencias y nuestros fines y valores. La pregunta acerca de si somos responsables de nuestras emociones no se dirige al hecho de tal o cual episodio emocional en un contexto particular determinado, sino al hecho de que en ese contexto el episodio sea de tal o cual emoción determinada. No somos responsables de estar en o pasar por episodios emocionales o de tener emociones. Ahora bien, ¿somos responsables de que nuestros episodios emocionales tengan tales o cuales características? Y en ese caso, ¿cuál es la naturaleza de la responsabilidad? Quizá no se nos pueda atribuir responsabilidad por haber creído (falsamente) que el River le ha ganado por cinco a cero al Boca Junior, dado que nuestra única fuente de información es el periódico del barrio, pero quizá sí se pueda exigir que cambiemos de periódico si la información errónea se convierte en habitual. La responsabilidad tendría que dirigirse al hecho del contenido de nuestras emociones en el sentido en que hemos manifestado en la sección anterior.

Hay dos actitudes prototípicas respecto a la racionalidad de las emociones (en adelante, mientras no sean necesarios los matices, podemos presuponer que las posiciones respecto a la racionalidad pueden extenderse a la moralidad, del mismo modo que los argumentos respecto a la moralidad y las emociones pueden extenderse a la racionalidad). La primera cabría identificarla de pesimista y la segunda de optimista. Por actitud pesimista entiendo la que considera que existe una diferencia radical entre la educación sentimental y el aprendizaje epistémico. Carlos Moya ejemplifica paradigmáticamente esta actitud:

«Podemos ejercer un control sobre la conducta derivada de emociones que no aprobamos [...] pero la emoción cuya expresión no permitimos no desaparece con ello y puede generar un conflicto interno que eventualmente da lugar al desequilibrio psíquico. Esto no significa que la educación sentimental esté condenada al fracaso desde el principio. Pero significa que el conflicto potencial entre racionalidad y emociones,

\footnotetext{
${ }^{17}$ Op. cit., véanse igualmente Greenspan, op. cit., y, sobre todo, J. Oakley, op. cit.
} 
entre la razón y la pasión, por utilizar los términos tradicionales, es en último extremo ineliminable. Una parte de la educación consiste en aprender a vivir con ese conflicto, aceptando la precariedad de la condition humaine. Significa, en segundo lugar, que la educación emocional es un arte, y no una ciencia, un proceso sujeto a contingencias azarosas y en el que la suerte no deja de desempeñar un papel» ${ }^{18}$.

Carlos Moya nos recomienda apretar los dientes y apechugar con nuestra frágil constitución, sabiendo que hay límites objetivos a nuestra capacidad de aprendizaje. Aunque no queda claro en qué sentido la educación epistémica pudiera llegar a ser una ciencia, a diferencia del arte sentimental, y tampoco queda claro en qué sentido el que sea un arte devalúa el valor del aprendizaje. Al fin y al cabo también es un arte el aprendizaje de los oficios y las artes, sin que por ello les tengamos menos aprecio que a presuntos aprendizajes científicos.

Un segundo tipo de pesimismos proviene de actitudes que calificaré de «neosartrianas». Es sabido que la teoría de las emociones de Sartre es que son el producto de un conflicto irresoluble entre la realidad y el deseo: se produce una emoción como una forma de protesta espontánea y quizás incontrolable a causa de que la realidad no es como desearíamos.

Amélie Rorty, Robert Solomon: las emociones serían estrategias condicionadas socialmente para enfrentarse a la realidad, pero se habrían transducido en corrupciones sociales de la mente ${ }^{19}$. El argumento de esta tradición neorracionalista tiene un aroma neokantiano innegable: la agencia es siempre intelectual y universalizadora, y si se desvía de su proyecto es a causa de alguna patología del yo, alguna patología social o ambas. La terapia de las pasiones sería una solución parcial cuando no puede controlarse la realidad: al menos controlar nuestros deseos.

La terapia de las pasiones que nos proponen los estoicos, después Kant y después muchos herederos en la línea davidsoniana, tiene mucho que ver con una triple conjunción de concepciones:

1. De las emociones como juicios sesgados de la realidad.

2. De la agencia racional como obediencia a normas explícitas de orden proposicional.

3. Del florecimiento humano como desarrollo intelectual.

Son bien conocidos los reproches que tiene Kant para toda teoría de la moralidad (y en nuestro caso de la racionalidad) que tenga como un cons-

${ }^{18}$ C. Moya, «Emociones, racionalidad y responsabilidad», 1998, manuscrito presentado en la reunión de la Sociedad Española de Filosofía Analítica. La cita no hace justicia al conjunto de su argumentación que implica una consideración global de la naturaleza de las emociones. Sin embargo, es una exposición perfecta de la posición de la que le consideramos representante.

${ }^{19}$ R. C. Solomon, «The politics of emotion», 1998, y A. O. Rorty, «Political sources of emotions: greed and anger», 1998, ambos en P. A. French y H. K. Wettstein (eds.), The philosophy of emotions. Midwest Studies in Philosophy XXII, Notre Dame, IN, University of Notre Dame Press, 1988. 
tituyente cualquier estado de componentes emotivos. La posición de Kant varía de una obra a otra sin abandonar nunca una innegable displicencia acerca del papel de las emociones. Una clara actitud antiemotivista la tenemos en la Fundamentación de la Metafísica de las Costumbres en la que leemos:

«En cambio, el sentimiento moral, ese supuesto sentido especial —aunque es harto superficial la apelación a este sentido, con la creencia de que quienes no puedan pensar habrán de dirigirse por medio del sentir, en aquello que se refiere a meras leyes universales, y aunque los sentimientos, que por naturaleza son infinitamente distintos unos de otros en el grado, no dan una pauta igual del bien y del mal, y no puede uno por su propio sentimiento juzgar válidamente a los demás-, sin embargo, está más cerca de la moralidad y su dignidad, porque tributa a la virtud el honor de atribuirle inmediatamente la satisfacción y el aprecio y no le dice en la cara que no es su belleza, sino el provecho, el que nos ata a ella» (Kant, 1785, edición en castellano de Francisco Larroyo, México, Porrúa, 1983, p. 53).

La distancia de Kant hacia los sentimientos morales, que tan cerca están de la felicidad, el sentimiento moral por excelencia, buscado como fundamento de la moralidad por muchas éticas no intelectualistas, está subordinada a lo que él pretende salvar, la capacidad deliberativa por encima del movimiento inducido por las pasiones, por benevolentes que puedan parecer. Así, en la Critica de la Razón Práctica, nos insiste que no es ni puede ser por el sentimiento de compasión por el que nuestra conducta merezca una buena calificación moral, sino por el sabernos respetuosos de una máxima que ha sido convertida en legítima tras sobrepasar el test de la universalidad:

«Es muy hermoso, por amor a los hombres y por benévola simpatía hacerles el bien o ser justo por amor del orden; pero eso no es aún la genuina máxima moral de nuestra conducta, la máxima conforme a nuestro criterio entre los entes racionales como hombres, si nos jactáramos, por decir así voluntariamente de pasar por encima de la noción de deber con arrogante imaginación, y como si fuéramos independientes de imperativos, y quisiéramos hacer solamente por propio agrado aquello a que no nos obliga ningún imperativo» (Kant, 1788, edición en castellano de Ansgar Klein, Buenos Aires, Losada, 1973, p. 89).

En la Metafísica de las Costumbres, su obra más cercana a lo que cabría de calificar como una filosofía práctica realista, en el sentido de Owen citado más arriba, desarrolla una teoría de las virtudes morales que se acerca mucho a la terapia estoica.

«En otro lugar (en el Berlinische Monatsschrift) creo haber reducido a la expresión más sencilla la diferencia entre el placer patológico y el moral, El placer que ha de preceder al cumplimiento de la ley para que obremos de acuerdo con ella, es patológico, y el comportamiento sigue entonces el orden natural; pero aquel al que ha de preceder la ley para que lo experimentemos, está en el orden moral» (Kant, 1797, edición en castellano de Adela Cortina y Jesús Conill, Madrid, Tecnos, 1989, p. 227). 
En los otros dos textos, que los autores más prokantianos admiten como algo excesivos, encontramos una clara subvaloración de los sentimientos en tanto que motivaciones no legítimas moral o racionalmente de las acciones. En la sofisticada Metafísica de las costumbres, que por el contrario muchos consideran como expresión del Kant más «humano», encontramos a mi parecer una posición metafísicamente mucho más dura: la legitimidad de los sentimientos depende única y exclusivamente de su posición en la cadena causal de la producción de la acción: si actúan previamente a la máxima, y por consiguiente aparecen en el orden de las causas como prioritarias al contenido de la máxima, son ilegítimos. Si aparecen, por el otro lado, como un subproducto causal de la acción debida a la máxima, un subproducto que se explica, ipobres de nosotros!, como una consecuencia de nuestra constitución psicológica, entonces son tolerables e incluso buenos. Pero esto equivale a expulsarlos del orden de las causas legítimas de la acción en un sentido moral o racional. Es como si Kant nos concediese que el hacer el bien puede ser bueno para nuestra salud, sin que la salud sea nunca un motivo justificable de la acción ${ }^{20}$.

Lo curioso de esta actitud es que la negatividad que muestran respecto de las pasiones es a causa de que paradójicamente reconocen que tienen cierto contenido evaluativo ${ }^{21}$ : es a causa de que son cuasi-juicios acerca de la realidad por lo que compiten con el sistema intelectual que realmente produce juicios legítimos. De manera que los pesimistas honran a las pasiones despreciándolas frente al juicio intelectual o moral. Y en el caso de Kant es muy claro que su teoría de la virtud como control intelectual de la pasión para adecuarla a la norma nace de su admiración por la teoría aristotélica de la virtud como equilibrio en el que la pasión se introduce como un componente necesario ${ }^{22}$, lo que a Kant le produce un insoportable horror. Pero Kant, y después de él todos los que adoptan esta posición, nos deben el argumento principal: ¿por qué habría de competir la evaluación racional con la evaluación emocional? Que compitan es para Kant un producto únicamente de su lugar en el proceso causal, pero no tiene argumento en relación con el contenido, es más, concede

${ }^{20}$ J. Oakley, «Kantian arguments against emotions as moral motives», 1988, en J. Oakley, $o p$. cit., discute las varias y complejas interpretaciones de Kant respecto a esta cuestión. N. Sherman, Making a neccesity of virtue. Aristotle and Kant on virtue, Cambridge, Cambridge University Press, 1997, propone una interpretación más compasiva con Kant. C. Thiebaut, en la misma línea, corrige mis entusiasmos aristotélicos y David Konstan, en su «Aristotle on pity and pain» (manuscrito) y en varias conversaciones muestra con su autoridad de filólogo a un Aristóteles mucho más cercano a Kant, de manera que estaría dispuesto a moderar mi poco fiable juicio histórico, aunque mantendría la división como tipos ideales.

${ }^{21}$ Esta observación está en C. Moya, 1998, que mediante ella se distancia de una solución meramente terapéutica para adoptar la solución dramática de aceptar el conflicto. Mi argumento contra Kant, sin embargo, se aplica también a su actitud. Cabría defenderse afirmando que una evaluación se produce por una intromisión externa en un juicio cognitivo, pero no se resolvería el problema, puesto que nos llevaría a una teoría humeana de que toda evaluación es irracional, «esclava de las pasiones».

${ }^{22}$ Es la posición de Nancy Sherman, op. cit. 
que en ocasiones pueden coincidir la evaluación emotiva y la intelectual. Pero si fuera el caso que las emociones mostrasen una evaluación coincidente con el juicio moral o racional, el que hayan estado al comienzo de la cadena causal no es en sí mismo un óbice para su racionalidad. Lo que puede decir con razón Kant es que su capacidad evaluativa está insuficientemente justificada, que no ha pasado aún los filtros de calidad de la deliberación, la única que permite pasar el test de la universalidad. Pero me parece que Kant es aquí excesivamente severo: de la insuficiencia no puede inferir la competencia.

El pecado contrario cometen los optimistas acerca de las emociones. La argumentación más elaborada me parece que es la del economista Robert Frank $^{23}$. Su argumento es que las emociones son soluciones a trágicos e insolubles dilemas de racionalidad. Como es bien conocido por los teóricos de juegos, cuando el resultado obtenido por nuestra acción depende de lo que otro u otros sujetos hagan qua sujetos, es decir, como agentes que son capaces de comprender y predecir nuestra propia decisión, lo que es el caso de la mayoría de las interacciones sociales, la racionalidad se encuentra ante dilemas no resolubles sin cambiar el concepto de racionalidad. El dilema del prisionero es el caso paradigmático. Su onda llega a la teoría de bienes públicos y acción colectiva y en el terreno personal a los conflictos inter-yoes a través del tiempo. Las emociones son, en forma de compromisos y lazos, o bien en forma de señales de que nuestra conducta se va a desviar de lo que cabe razonablemente esperar, mecanismos que desenredan el nudo gordiano propuesto por el dilema.

Pero, y aquí cabe traer a colación los argumentos de Elster, del hecho que sean mecanismos, por ejemplo, de compromiso, y del hecho que sean mecanismos que resuelven cuellos de botella en la dinámica de las decisiones individuales o colectivas, no se deriva que sean mecanismos por sí mismos racionales y/o morales. Daniel Goleman ${ }^{24}$, en la misma línea de Robert Frank, ha alcanzado un notorio éxito con su obra Inteligencia emocional en la que divulga las principales investigaciones, hipótesis o comentarios filosóficos de la más cercana contemporaneidad acerca de las emociones. Pero inmediatamente se desliza por la resbaladiza pendiente del optimismo y nos propone una «inteligencia emocional» y algunos consejos para mejorarla, lo que, dicho sea de paso, hace peligrar su libro en las oscuras arenas de la literatura de autoayuda. Pero obsérvese hasta qué punto puede ser peligroso postular tal inteligencia: si por inteligencia emocional entendemos la capacidad de movilizar los recursos y reacciones emotivas de los empleados para conseguir que trabajen, no hay mucho de inteligencia en el asunto: amedrénteselos, aterroríceselos, póngase su vida en peligro cada segundo y la empresa marchará. ¿Quién ha dicho que un campo de concentración no es una exhibición de inteligencia

\footnotetext{
${ }^{23}$ R. Frank, Passions within reasons. The stragtegic role of the emotions, Nueva York, Norton \& Co., 1988.

${ }^{24}$ D. Goleman, Emotional intelligence, Nueva York, Bantham, 1995 (trad. castellana en Barcelona, Kayros).
} 
emocional? Y si, por el contrario, lo que pretendemos es decidir qué emociones son las más adecuadas, los kantianos tienen razón: delibérese.

Los optimistas emotivistas cometen el pecado contrario que los neoestoicos: enaltecen a las emociones subrayando tanto su papel de daimones autónomos que las devalúan como objetos de deliberación moral, pues si las emociones son las soluciones a los graves dilemas de la vida personal y colectiva es que la vida personal y colectiva no tiene solución racional. No hay diferencia en decir que las emociones lo arreglarán o que el tiempo lo arreglará.

\section{La educación sentimental como expansión de la disponibilidad}

Reconsideremos de nuevo los pasos de nuestra presentación. Comenzamos estableciendo unidades largas, históricas, narrativas como dominios legítimos de evaluación racional y moral. Determinamos que las emociones constituyen un sistema funcional complejo que porta una cierta clase de representaciones descriptivo-directivas con un contenido preconceptual que constriñe ulteriores reformulaciones conceptuales. A continuación hemos criticado a las posiciones pesimistas por no saber acomodar adecuadamente el contenido emotivo en la economía de la racionalidad y moralidad; y a las posiciones optimistas por rebajar el status agencial del contenido emotivo a mero mecanismo evolutivo. Nuestro argumento es que necesitamos concebir el contenido emotivo de manera suficientemente robusta para que sean susceptibles de evaluación normativa (racional, moral) y al mismo tiempo lo elementalmente primitivos como para situarse en un nivel preconceptual. Pues, no lo olvidemos, el objetivo es que los contenidos emotivos contribuyan a la racionalidad y moralidad de las trayectorias largas en nuestras vidas individuales y colectivas.

La principal objeción de los pesimistas es el argumento del control que ha esgrimido Carlos Moya: si no podemos controlar los episodios emotivos, si tienen su propia lógica, entonces no se nos puede exigir responsabilidad acerca de ellos, puesto que son paralelos, ajenos al dominio normativo de la racionalidad/moralidad. Es un argumento que, como dijo Borges de Berkeley, no admite la menor réplica ni produce la menor convicción. Reparemos en que la lógica que subyace al uso irrestricto del argumento del control puede ser autosocavante, pues cada vez una parte del contenido mental que causa una decisión estuviera más allá de control habría considerar que las consecuencias están más allá de la responsabilidad, lo que muestra cuán restrictivo es este criterio internista de racionalidad y responsabilidad. El defecto está en la equivalencia de control voluntario y responsabilidad racional o moral. De un lado, porque si limitamos la responsabilidad a aquello que está bajo el control nos vemos abocados a una forma de racionalidad mínima.

Que la equivalencia de control y responsabilidad devalúa nuestra noción de racionalidad es algo que puede verse muy fácilmente incluso para la racionalidad epistémica e inferencial. Es sabido que realizamos las inferencias bajo 
tales constricciones de tiempo y falta de información que violaríamos todas las leyes de la lógica sistemáticamente a menos que confiemos en lo que los lógicos llaman inferencias por defecto. En tales inferencias se presta atención solamente a algunos rasgos de la información (suficientes para mantener la consistencia) dejando otros sin comprobar ${ }^{25}$. Pero esta noción mínima de racionalidad que nos exime de responsabilidad más allá de los límites de la memoria activa es engañosa. En la vida cotidiana nos autoexigimos más, y para ello nos ayudamos de transferencias de información al exterior en forma de escritura, máquinas o mecanismos de cómputo, de la mente de otras personas, y de innumerables métodos que habilita nuestra «mente extendida». Lo hacemos porque nos sabemos responsables de muchas inferencias a pesar que no podamos controlar individualmente toda la información. De manera que el criterio estricto de control tiene de hecho consecuencias perversas que sus bienintencionados defensores no parecen haber notado: nos deja exentos de una responsabilidad que a todas luces nos es imputable ${ }^{26}$.

La ruptura de la equivalencia del control y la responsabilidad no entraña que no existan relaciones de dependencia. En otro caso se podrían exigir responsabilidades de acciones o inferencias que están ilimitadamente más allá de nuestro control ${ }^{27}$. Pero al tiempo somos en algún modo responsables de cosas que no controlamos de forma inmediata. Así, se nos pueden exigir responsabilidades por los sistemas de seguridad en una empresa, aunque no hayamos podido controlar el accidente. Éste es uno de los sentidos en los que control y responsabilidad no son coextensionales.

Lo racional no es controlar siempre, sino encontrar medios para llevar a cabo lo que es adecuado a la circunstancia. El control de las emociones, desde este punto de vista, podría resultar tan equivocado como su descontrol. El camino para soslayar el automatismo de las emociones, que tanto asusta a los partidarios del estoicismo, sería una norma de racionalidad que no se limite a un conjunto de normas, sino que proponga condiciones de adecuación

\footnotetext{
${ }^{25}$ El ejemplo que siempre se repite es «Todos los pájaros vuelan, Tweety es un pájaro, luego vuela» (pero podría resultar que Tweety fuera un pingüino, en vez del malévolo canario que siempre escapa al gatito).

${ }^{26}$ Además, no somos responsables de muchas acciones cuya producción controlamos. En los casos de agencia colectiva, en los que el resultado depende de las interpretaciones y predicciones mutuas de los agentes, el control individual no nos hace responsables de los nefastos resultados que pueda tener nuestra acción, por racional que pueda ser de acuerdo a cualquier máxima. Es el caso de la versión estándar del dilema del prisionero, aunque también hay casos de dilema del prisionero en contextos colectivos en que la máxima universalizadora de tratar a los demás como uno quisiera ser tratado es un desastre: por ejemplo, si en medio de una multitud sufre un accidente una persona, lo mejor es que el número de altruistas sea pequeño y suficiente: más altruistas de lo debido solo conduce a imposibilitar la ayuda.

${ }^{27}$ Esta objeción a mi posición se debe a Carlos Moya en comunicación privada. No puedo argumentar en el espacio de este trabajo a favor de las relaciones de dependencia entre responsabilidad y control diferentes a la equivalencia. Baste decir aquí que necesitamos expandir la noción de control a una acción preventiva sobre nuestros sistemas de control estrecho y actual.
} 
similares a las de cualquier otra virtud. Desde esta perspectiva, la calificación de racional a una decisión o a un proceso sería un calificativo de logro o éxito que sobreviene a procesos múltiples de interacción informacional interna y externa. Así, no sería necesariamente racional quien se atuviera únicamente a sus «razones» (las comillas indican el contenido interno autorrepresentado), pues podría ocurrir que tuviese graves déficits en los sistemas de generación de las creencias y deseos.

Es aquí donde debemos recobrar nuestro análisis del contenido preconceptual emotivo como un contenido descriptivo-prescriptivo. El complejo emocional conforma un sistema de capacidades de respuesta a estímulos de múltiple formato: del medio, de la imaginación, de la imaginación del estado mental de otros, etc. Si el sistema perceptivo conforma un complejo de capacidades recognoscitivas, que interactúan con los conceptos y con las habilidades prácticas al tiempo que con el mundo, también el sistema emotivo conforma un complejo de capacidades. Pero en este caso son capacidades de respuesta a percepción de situaciones. Hay algo de perceptual y algo de disponibilidad a la respuesta adecuada.

La adecuación debe evaluarse en términos largos, narrativos. No se diferencia en esto de las funciones referidas al comportamiento orgánico: ¿qué significa estar sano?, ¿no debemos cualificar la respuesta por edades, por medios, relativamente a la población, a un sistema de prevención, a una historia ontogenética del organismo, etc.? La relatividad del término «salud» no implica, sin embargo, que la vaguedad de los diagnósticos nos sea insoportable, al contrario, cabe definir los déficits de salud con una aceptable propiedad. Algo similar puede pasar con la idea de racionalidad: involucra una forma de equilibrio múltiple cognitivo que sobreviene al buen funcionamiento de sistemas muy diferentes y la coordinación adecuada entre los subsistemas. Por supuesto que la conciencia reflexiva es muy importante, mucho, pero convendría no cargarla con la equivalencia de control y responsabilidad que acabamos de comentar. La conciencia reflexiva examina la información a la que puede acceder, pero tal información ya está mediada por relaciones de relevancia, por la propia traducción al formato conceptual, etc. El sistema emotivo, al interactuar con los sistemas superiores, conforma los contenidos adhiriendo a ellos estos contenidos RDD que son los eventos emocionales.

Esta dependencia de la relevancia cognitiva respecto a los contenidos que conforman el transfondo ata la dinámica de la creencia a los avatares de la historia y experiencia emotiva del agente. Pero en la dirección contraria tenemos que las experiencias emotivas se mezclan y constituyen nuevas capacidades de respuesta: las emociones se configuran, se afinan, detectan más o menos eventos y se hacen más o menos discriminativas. Las capacidades discriminativas del sistema afectan tanto al sistema conceptual como al emotivo ${ }^{28}$. Los psi-

${ }^{28}$ La principal fuente de cambio del sistema emotivo proviene de una de nuestras principales facultades: el módulo de interacción social que los psicólogos denominan Teoría de la Mente, 
cópatas sociales, que pueden llegar a tener una aceptable capacidad de convivencia social, tienen, sin embargo, un déficit notorio en la simulación de los sentimientos ajenos. No es imposible pensar en un sociópata kantiano que actuase de acuerdo a máximas, pero cabría seguir sosteniendo que tal ser aún tendría un déficit en la adecuación de sus sistemas racionales.

La diferencia que sostenemos con las teorías intelectualistas está en los componentes cartesianos de su concepción de lo mental, está también en la idea de que solamente hay racionalidad/moralidad en el terreno de los contenidos conceptuales representables, pero me parece que la discrepancia se encuentra en un estrato aún más profundo que tiene que ver con el mito de que el florecimiento humano es intelectual o no lo es. Si nuestras vidas están condenadas al fracaso e impotencia sentimental, si, colectivamente, como el proletariado parisino, el dolor y las lágrimas son solamente subproductos ocasionales de la astucia de una presunta capacidad de cálculo «racional», es que nuestros sistemas de decisión tienen algún déficit que deberíamos examinar cuanto antes. La otra alternativa une nuestras capacidades internas a las oportunidades que abren los espacios del medio que nos rodean. La racionalidad consistiría entonces en una capacidad perceptiva para visualizar esas oportunidades y en la disponibilidad para aceptar o, eventualmente, rechazarlas y la capacidad para hacernos cargo de ellas. Y no en otra cosa reside nuestra educación sentimental.

la capacidad de interpretar y predecir la conducta ajena en función de sus estados mentales. Sobre la relación entre la TM y las emociones, véanse, P. L. Harris, Los niños y las emociones, Madrid, Alianza, 1992; N. Sherman, «Empathy and imagination», en French y Wettstein (eds.), op. cit., 1998; R. M. Gordon, «Sympathy, simulation and the impartial spectator», 1996; A. I. Goldman, «Simulation an interpersonal utility», 1996, y J. Deigh, «Empathy and universabilility», 1998, todos ellos en L. May, M. Friedman y A. Clark (eds.) Mind and morals. Essays on Ethics and Cognitive Science, Cambridge, Ma. MIT Press. 